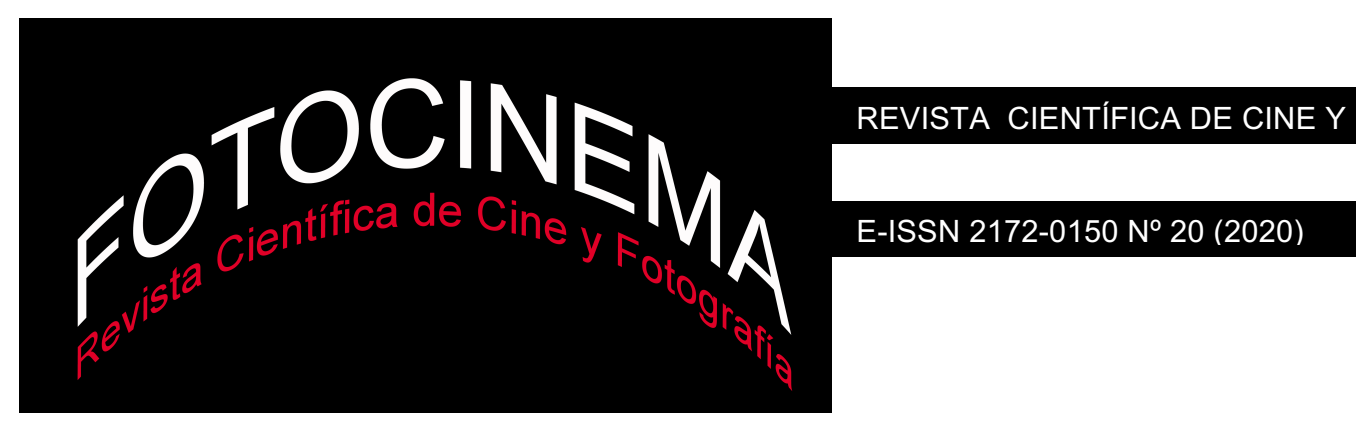

\title{
El cortometraje latinoamericano moderno. Registro, dispositivo, documento y memoria
}

\section{The modern Latin American short film. Registration, device, document and memory}

\author{
Javier Cossalter \\ Consejo Nacional de Investigaciones Científicas y Tecnológicas (CONICET) / \\ Universidad de Buenos Aires (UBA), Argentina. \\ javiercossalter@gmail.com
}

\section{Resumen:}

El cortometraje, de acuerdo a sus potencialidades económicas y estructurales, tuvo un rol destacado en la transformación del campo cinematográfico latinoamericano durante las décadas del cincuenta y sesenta, tanto en la renovación estética como en el compromiso social. El objetivo de este trabajo consiste en analizar un corpus de cortos documentales argentinos, brasileños y mexicanos junto a sus condiciones de producción con el interés de efectuar una doble reflexión en torno a la dimensión política y patrimonial de este cine. En primer lugar, se focalizará en el perfil observacional de la cámara, el montaje, el testimonio y las voces como elementos expresivos tendientes a registrar una problemática social en el presente de gestación del film e intervenir en dicha realidad. En segundo lugar, y de forma complementaria, se colocará la atención en el carácter mnemónico del corpus y la construcción de un documento cultural para la posteridad, teniendo en cuenta no sólo la propia textualidad de los films sino también la conciencia patrimonial de las entidades de producción y difusión en cada país.

\begin{abstract}
:
The short film, according to its economic and structural potentialities, played a leading role in the transformation of the Latin American film field during the fifties and sixties, both in aesthetic renewal and social commitment. The proposal of this work is to analyze a corpus of short Argentine, Brazilian and Mexican documentaries together with their production conditions with the interest of making a double reflection on the political and heritage dimension of this cinema. In the first place, it will focus on the observational profile of the camera, the edition, the testimony and the voices as expressive elements tending to register a social problem in the present of gestation of the film and intervene in that reality. Secondly, and in a complementary way, attention will be placed on the mnemonic character of the corpus and the construction of a cultural document for posterity, taking into account not only the textuality of the films but also the heritage awareness of the entities of production and diffusion in each country.
\end{abstract}

Palabras clave: cortometraje moderno; cine Latinoamericano; cine social y político; documento; patrimonio cultural; memoria.

Keywords: Modern Short film; Latin American Cinema; Social and Political Cinema; Document; Cultural Heritage; Memory. 


\section{Introducción}

Hacia mediados/finales de la década del cincuenta se produjo una reconfiguración del campo cultural latinoamericano caracterizada por un marcado espíritu modernizador y una creciente efervescencia social, rasgos que permiten acercarnos temporal y espacialmente a la región desde la noción de época (Gilman, 2003)ํ. Como parte de dicho estado de situación, el cine latinoamericano experimentó cambios profundos en los modos de producción y una preocupación explícita por redescubrir el lenguaje cinematográfico que se combinó, de manera progresiva, con un manifiesto compromiso social.

En este sentido, y si bien la historiografía tradicional del cine ha consensuado el origen del Nuevo Cine Latinoamericano en 1967, plasmado en el hito que significó el Festival de Viña del Mar, ciertos atributos de comunión regional pueden rastrearse ya desde mediados de los años cincuenta (Cossalter, 2017b, pp. 499-500).

Esta conjunción original de nuevas disposiciones económicas, estéticas y políticas mantuvo una relación de directa afectación y retroalimentación con las innovaciones tecnológicas arribadas por aquel entonces. Tales novedades -que incluían la disponibilidad de nuevas emulsiones de película, cámaras más livianas y la viabilidad para tomar sonido sincrónico- significaron, sobre todo en el terreno del documental, una revolución tecnológica similar a la producida por la llegada del sonido a fines de los años veinte.

Ahora bien, tanto en países que habían forjado una fuerte tradición fílmica industrial como en aquellos de producción discontinua o intermitente (Paranaguá, 2003), el impulso modernizador y el anclaje político encontraron su desarrollo dinámico en un común denominador: la participación activa del cortometraje con predominancia en circuitos alternativos. El film breve, gracias a sus potencialidades económico-

\footnotetext{
${ }^{1}$ Este concepto devela la conciencia de una sociedad que comparte un horizonte esperado de transformaciones en el campo de la cultura y que determina el discurso de lo deseable. En palabras de Claudia Gilman, el término puede utilizarse como una herramienta para pensar la "convergencia de coyunturas políticas, mandatos intelectuales, programas estéticos y expectativas sociales" (2003, p. 36) en América Latina durante las décadas del sesenta y setenta.
} 
estructurales y en conjunción con el modelo documental, se convirtió en un medio de expresión permeable a la serie social cuya productividad se asentó en el rescate de identidades marginales, la crítica y la confrontación de situaciones conflictivas. No obstante, su función primordial y prioritaria en tanto herramienta de registro audiovisual devenida en vehículo de aprehensión y/o acción social no excluye la consideración de su dimensión mnemónica y patrimonial.

En este sentido, el propósito del presente trabajo consiste en analizar un corpus de cortometrajes documentales modernos de Argentina, Brasil y México $^{2}$-países exponentes en la región de un cine con tradición industrial sostenida- que abordan problemáticas sociales e identidades marginales en el presente de su confección. De este modo, en primer lugar, la intención es examinar la capacidad del film breve para actuar como medio de registro y dispositivo de aprehensión en diversas condiciones de producción y contextos socio-culturales. Prácticamente por fuera de la institución dominante, gracias a su marginalidad económica y su relación inmediata con el receptor, el corto pretendió funcionar como un medio eficaz de concientización en la región. Ahora bien, en segunda instancia, de forma consciente o de modo indirecto, estas obras se transformaron en documentos históricos anclados no en la recuperación del pasado sino en la conformación de un patrimonio del presente. Por tal motivo, es posible abordar dicha producción desde una perspectiva que coloque el foco de atención en la construcción de una memoria social y cultural.

Entonces, con la finalidad de llevar a cabo esta doble reflexión acerca del corto latinoamericano moderno -registro/dispositivo y documento/memoria-, dividiremos el artículo en tres secciones, sustentadas en conceptualizaciones teóricas particulares y análisis de caso. En la primera parte revisaremos las potencialidades estructurales del film breve en conjunción con el modelo documental y las innovaciones tecnológicas. En el

2 El corpus es el siguiente: ARGENTINA: Tierra seca (Oscar Kantor, 1962) y Ceramiqueros de Traslasierra (Raymundo Gleyzer, 1965); BRASIL: Arraial do Cabo (Mário Carneiro \& Paulo César Saraceni, 1959) y Maranhão '66 (Glauber Rocha, 1966); MÉXICO: Mural efímero (Raúl Kamffer, 1968). 
segundo apartado efectuaremos el análisis del corpus dentro del marco sociocultural de producción de las tres cinematografías escogidas, para observar las funciones del film breve documental en tanto registro, dispositivo (Dittus Benavente, 2012) y agente de la historia (Ferro, 1980). En el último punto, teniendo en cuenta las entidades de producción y difusión de las obras, llevaremos adelante la reflexión final en torno a la concepción patrimonial y mnemónica del corto documental latinoamericano a través de, principalmente, las nociones de patrimonio del presente (Colin, 2014), la memoria como trabajo y su vínculo con la identidad (Jelin, 2002), y el audiovisual como proceso y soporte de la memoria (Guarini, 2002).

\section{El film breve documental: un medio de expresión marginal, efectivo y expeditivo}

En los comienzos del cinematógrafo el cine era corto debido a una cuestión técnica3 ${ }^{3}$ La distinción de metrajes se volvió operativa con el surgimiento de la industria fílmica y la consideración del largometraje como verdadera mercancía capaz de generar rentabilidad. El film breve, entonces, continuó siendo la medida apropiada para contener al género informativo y por sobre todo fue relegado hacia los márgenes del cine comercial, redescubriendo su fertilidad en producciones que trascendían las fronteras de la convención. No obstante, como bien señala Paulo Pécora: "Cortometraje es sólo la denominación institucional que se le dio desde entonces a una obra cinematográfica corta, pero su especificidad no está en su característica física más obvia, sino más bien en su carácter de refugio y espacio de resistencia” (2008, p. 380). Esta original concepción del film breve nos permite romper con los rótulos tradicionales y pensar acerca de sus rasgos singulares.

En principio, puesto que la duración no define de forma esencialista al metraje, descartamos el término formato para referirse al cortometraje, el cual apunta meramente a la cuestión del tamaño. Más aún, no comulgamos

3 Cabe resaltar que toda referencia al cortometraje en este trabajo se restringe al soporte en fílmico. Posteriormente, la aparición del video y más tarde de la tecnología digital abrieron un campo novedoso de posibilidades -de producción, distribución, exhibición y estructura estética interna- que necesariamente requiere de nuevos enfoques teóricos y de análisis. 
con la noción de género, etiqueta principal que suele utilizarse para designar al film breve. En relación a ello nos preguntamos: ¿es equiparable una tipología normativa como el western o el melodrama -que construyen su propio verosímil- con la multiplicidad de estilos, temas y formas expresivas que puede ofrecer el corto? Absolutamente no. En discordancia con estas conceptualizaciones sostenidas por una perspectiva del cine puramente comercial, preferimos entender al film de corta duración como un medio de expresión audiovisual que manifiesta ciertas cualidades potenciales.

En términos económico-productivos, el abaratamiento de los costos debido a una utilización menor de celuloide y, generalmente, un equipo reducido de trabajo, es un aspecto a favor que debe convivir con el corrimiento del corto hacia los márgenes de la industria y su escasa o nula rentabilidad, lo cual complica su financiamiento generando un mayor sacrificio monetario. Ahora bien, esta marginalidad y su consecuente ausencia de condicionamientos comerciales le conceden a este una mayor libertad estética. En palabras de Annemarie Meier, "por lo menos en las fases de diseño y producción el cortometraje cuenta con un margen de independencia que permite la libertad de creación" (2013, p. 6). Esta apertura de horizontes se refleja en la posibilidad de explorar el lenguaje cinematográfico de manera dinámica, abordar temáticas restringidas o poco comunes y tomar ciertos riesgos en torno al enfoque socio-político e ideológico. Por otra parte, en conexión con la disposición estética debemos citar las potencialidades estructurales del cortometraje. En este punto la duración constituye un elemento determinante para comprender su organización interna. En primera instancia, la dimensión temporal reducida no actúa como una limitación. El corto no es un pequeño largometraje. Efectivamente se produce una adecuación del acontecimiento/historia a la duración. No necesariamente todo aquello que se sostiene con coherencia y organicidad en un relato de más de una hora lo hace con la misma eficacia en un lapso de tiempo reducido, ni contrariamente. Sí podemos observar que en el corto se efectúa habitualmente una compresión y una condensación del tiempo que le imprimen más intensidad al contenido y mayor destaque a la forma 
expresiva. Por último, la estructura del cortometraje puede predisponer al receptor para que asuma una actitud atenta y una posición cognitivosensorial activa, continuando el proceso reflexivo en su mente (Bergese, Pozzi \& Ruiz, 1997).

Ahora bien, algunos de estos aspectos resultan favorecidos y reforzados en su enlace con el cine documental. Fundamentalmente este comparte con el corto la marginalidad económica e institucional. Vicente Benet (2008) reflexiona sobre el documental en tanto otro modelo cinematográfico, puesto que lo piensa en contraposición a la ficción, que sería el predominante. Se trata de un modelo periférico situado al margen de la industria cinematográfica. Dentro de la variante del cine social y político, sumado a la marginalidad y el bajo presupuesto, la condensación de los tiempos, la efectividad y la relación que se establece con el receptor cobran también relevancia. Los films de carácter etnográfico y aquellos de índole contestataria circulaban por fuera de los límites de la industria, no estaban destinados a la recuperación comercial y sus propósitos podían llevarse a cabo con un presupuesto mínimo. Las cualidades estructurales del corto han posibilitado cobijar con eficacia los caracteres de este cine. El corto documental socio-político, a través de una conexión directa, inmediata y efectiva con el auditorio, procura construir un destinatario activo en tanto componente dinámico del proceso de comunicación, sobre el cual recae la responsabilidad y el compromiso de la reflexión, la toma de conciencia y/o la determinación de acción. Aquí entra en juego el concepto de efectividad en una doble articulación: como atributo del corto en cuanto al contacto fluido entre enunciador y enunciatario dentro de esta estructura breve, y como criterio político cuyo sentido fue acuñado por Susana Velleggia (1986), el cual apunta a las consecuencias extra-cinematográficas que se desprenden de la relación del cine con sus destinatarios.

Por otra parte, colocando el foco en el contexto de producción cinematográfica en América Latina hacia finales de la década del cincuenta, esta voluntad particular que vislumbró el cortometraje documental por brindar voz e imagen a sujetos segregados anteriormente ausentes en la 
imagen fílmica, rescatar identidades marginales y retratar situaciones de conflicto social, responde no solamente a un espíritu de época sino que es posible principalmente gracias a los avances tecnológicos que arribaron para finales de década $\mathrm{y}$, en algunos casos, con cierto retraso. Tres factores centrales sobresalen. En primer lugar, la aparición de nuevas emulsiones de película que renovaron las técnicas de rodaje. Consistía en una película más sensible que permitía filmar con luz natural. Es decir, se podía rodar en exteriores naturales sin ningún aditamento ni mayores complicaciones. Esto se conecta directamente con la segunda renovación técnica: la utilización de cámaras más livianas que posibilitaban una mayor movilidad. La facilidad de traslado de estas cámaras fue una condición indispensable para que el cine pudiera captar realidades recónditas. Finalmente, la disponibilidad de los nuevos magnetófonos Nagra hicieron viable la toma de sonido directo. En este sentido, el sujeto/actor segregado estaba en condiciones de brindar testimonio en su ámbito cotidiano de vida y de trabajo. No obstante, dicho avance tecnológico tuvo ciertas dificultades para su aplicación inmediata en algunos sectores de la región.

De este modo, la conjunción del cortometraje, el documental y las innovaciones técnicas en América Latina en el contexto de modernización cinematográfica y transformación social dinamizaron una tendencia de registro, reflexión y voluntad de acción.

\section{El corto latinoamericano moderno: vehículo de exploración e intervención socio-cultural}

De acuerdo a lo expresado en la introducción, si bien suele marcarse el comienzo del Nuevo Cine Latinoamericano a fines de la década del sesenta,4 es posible insertar a nuestro objeto de estudio dentro del marco de este

\footnotetext{
4 Mariano Mestman (2016) coordina un libro que explora las rupturas alrededor del 68 en el cine de América Latina, donde propone "interpretar los procesos de emergencia y confrontación de las rupturas en relación con realidades políticas y configuraciones culturales nacionales" (2016, p. 16), enfocándose en las especificidades y vinculaciones de los cines de la región. Previo al contexto de radicalización política en el terreno latinoamericano puede asimismo pensarse al cine regional desde un enfoque comparativo en torno al registro de la realidad social.
} 
fenómeno, tomando particularmente las consideraciones que Zuzana Pick (1993) y Silvana Flores (2013) formulan al respecto. Por un lado, Pick comprende al Nuevo Cine Latinoamericano en tanto un proyecto continental y distingue diversas fases en su desarrollo así como postula distintos parámetros transversales reconocibles en las diferentes cinematografías, colocando el foco de atención en la modernización del lenguaje y la politización. Por otro lado, Flores ahonda en las apropiaciones foráneas que sustentan la renovación fílmica durante las décadas del cincuenta y sesenta, y el extenso corpus de films latinoamericanos que examina evidencia la relevancia que el cortometraje alcanzó en este período. En este sentido, "el Nuevo Cine Latinoamericano no nació de la noche a la mañana, y el corto documental de los años cincuenta y sesenta tuvo un peso sustancial en la gestación de dicho fenómeno" (Cossalter, 2017b, p. 500).

De particular interés resulta entonces este encuentro entre la revolución tecnológica, el documental y la renovación cinematográfica de la modernidad; cruce que halló en el cortometraje y sus caracteres un espacio propicio para su desenvolvimiento. Tres distintivas innovaciones expresivas, provenientes de corrientes extranjeras, impactaron en este cine tendiente a retratar y transformar la realidad social imperante5: la cámara como observadora, la palabra del otro y la autoconciencia enunciativa. El primer procedimiento es la piedra angular del direct cinema estadounidense, en donde se pretende observar la realidad sin intervenir en ella. Es decir, se captura a los sujetos pero la cámara se restringe al registro de los mismos. El segundo recurso es el que sostiene al cinéma vérité francés, en el cual el documentalista no registra una situación, sino que va y la provoca. El sujetoprotagonista ya no es un simple objeto de contemplación. Su palabra cobra protagonismo $^{6}$. Finalmente, la autorreflexión del medio, característica central de la modernidad cinematográfica, también se hizo presente. Según David Bordwell (1996), el cine histórico-materialista soviético eclosionó en el

\footnotetext{
5 Asimismo, en correlato con estos postulados, algunos rasgos del neorrealismo italiano fueron apropiados.

${ }^{6}$ Con el propósito de analizar de forma pormenorizada las apropiaciones del direct cinema y el cinéma vérité en el documental argentino y latinoamericano de las décadas del sesenta y setenta se recomienda la lectura de Mestman (2010).
} 
cine político de los años sesenta otorgando el marco temático y formal de un cine autoconsciente y comprometido socialmente. La narración autoconsciente del cine soviético clásico se amalgamó con los objetivos perseguidos a través del uso de intertítulos, dibujos, canciones, planos congelados, una cámara autónoma y principalmente la presencia explícita del montaje. A su vez, el esfuerzo cognitivo por parte del receptor fue otro de los rasgos de este cine recuperado por el corto documental latinoamericano de la época, el cual se articula de forma dinámica con el concepto de efectividad presentado con anterioridad.

Ahora bien, todas estas disposiciones potencian la condición del cine como agente de la historia (Ferro, 1980). El retrato de las condiciones de vida y de trabajo de comunidades marginales, el registro de las manifestaciones contra-culturales y de los conflictos sociales son acciones que presumen una clara intencionalidad, ya sea la puesta en valor, la crítica, la denuncia, la contrainformación, la concientización o la agitación. Es decir, pretenden influir en la sociedad e intervenir en ella generando algún tipo de respuesta. Por tal motivo, resulta pertinente considerar la noción de dispositivo aplicada al medio audiovisual7. Concretamente, a favor de nuestro objeto de estudio, Rubén Dittus Benavente (2012) toma las formulaciones teóricas de Giorgio Agamben y de Jean-Louis Baudry para afirmar que "cualquier cosa que tenga la capacidad de orientar, capturar o modelar el pensamiento y de generar estados mentales es un dispositivo. Siguiendo ese razonamiento, el cine documental político asoma como uno de los más eficaces mecanismos de creación de subjetividad" (2012, p. 83). En definitiva, el cine como dispositivo se aboca a los efectos de control que la instancia de producción procura aplicar en el terreno de la recepción. Y justamente el documental político -a través de procedimientos narrativos, enunciativos y estéticos como los analizados- busca orientar de forma particular el vínculo entre la audiencia y el referente. En esta senda, el cortometraje, gracias a sus potencialidades, reafirma aún más la virtud del cine en tanto dispositivo.

\footnotetext{
7 Jean-Louis Baudry (1975) fue el primero que reflexionó sobre este concepto en el campo cinematográfico. Desde una perspectiva metapsicológica, el autor entendía que el film provocaba un efecto en el espectador.
} 
Con el objeto de explorar este corpus heterogéneo y a la vez representativo de films deberíamos tener en cuenta que las tres cinematografías apuntadas en este artículo habían desarrollado una tradición industrial sólida entre las décadas del treinta y del cincuenta, y que impulsaron inicialmente la renovación de sus cines a través del cortometraje producido al interior de circuitos alternativos -talleres, centros y escuelas de cine-. No obstante, y a pesar del marco socio-cultural compartido, el abordaje de las problemáticas sociales se desenvolvió conforme a especificidades y particularidades locales ${ }^{8}$.

En Argentina, previo a la radicalización política desatada como consecuencia del golpe de Estado autodenominado "Revolución Argentina” acaecido en 1966 y la conformación de los colectivos de realización clandestinos, dos entidades singulares sustentaron, acogieron $\mathrm{y}$ financiaron a un corto renovador que buscaba retratar la realidad social de los marginados9: el Fondo Nacional de las Artes ${ }^{10}$ y las escuelas de cine dependientes de Universidades Nacionales ${ }^{11}$. Tierra seca (Oscar Kantor, 1962) fue financiado por el FNA. Y si hablamos de registrar una realidad social, este corto, en principio, pone en juego una serie de procedimientos en función de la mostración y constatación de una problemática local/regional contemporánea a la factura del film. Concentrado en La Quiaca, provincia de Jujuy, ${ }^{12}$ y despojado de voces over narradoras, típicas del documental

8 Para profundizar en el estudio comparado del cortometraje moderno argentino y latinoamericano, véase: Cossalter (2015, 2017b, 2018a, 2018b, 2019).

$9 \mathrm{El}$ presente enfoque y la posterior reflexión en torno al carácter patrimonial y mnemónico puede hacerse extensible a un corpus mayor de cortos documentales argentinos de este período. Señalamos, entre otros, a Tire dié (Fernando Birri, 1958), Fiesta en Sumamao (Aldo Luis Persano, 1961), Reportaje a un vagón (Jorge Goldenberg, 1963), Casabindo (Jorge Prelorán, 1965), Hachero Nomás (Jorge Goldenberg, Hugo Luis Sonomo, Patricio Coll y Luis Zanger, 1966), Chucalezna (Jorge Prelorán, 1968), Pescadores (Dolly Pussi, 1968).

10 Creado en 1958, esta institución dispuso un Fondo de Fomento para estimular una producción de cortos tendiente a relevar diferentes disciplinas artísticas del país y rescatar las identidades regionales.

${ }^{11}$ La Escuela de Cine de la Universidad Nacional de La Plata fundada en 1956; el Instituto de Cinematografía de la Universidad Nacional del Litoral, en 1957; y el Departamento de Cine de la escuela de Artes de la Universidad Nacional de Córdoba, en 1964, son los tres centros de aprendizaje más importantes del período que se encargaron no sólo de formar jóvenes realizadores sino de brindarles las herramientas para plasmar auténticamente la realidad.

12 Este film breve anticipó el Relevamiento Cinematográfico de Expresiones Folclóricas Argentinas que pocos años después -entre 1963 y 1967- llevaría a cabo el Fondo Nacional de 
expositivo, el relato le confía a la cámara la capacidad plena para ejecutar el acto narrativo-audiovisual mediante la observación directa de los acontecimientos. El conflicto particular se nuclea en torno al éxodo forzado que sufre una familia para ir a trabajar en la zafra, aunque el mismo desborda lo individual para insertarse dentro de un contexto desfavorable general, expuesto al comienzo por los intertítulos a modo de leyenda: "Son sus protagonistas los descendientes de los primeros habitantes de nuestra América. La tierra, el agua, los caminos, la mina, fueron suyos. Ahora, obligados por la miseria bajan de sus pueblos para contratarse en la zafra”. Es la cámara la que vislumbra, por medio de planos extremadamente abiertos, la inmensidad avasalladora del espacio geográfico árido y la pequeñez de los sujetos indefensos que allí habitan. Por momentos se trata de meras postales en movimiento; cuadros vivientes cuya composición advierte una tensión. Luego, estas imágenes se articulan con un montaje de planos cortos en donde se presenta a los protagonistas que intentan trabajar la tierra. El diálogo, prácticamente ausente en todo el relato, se instala fugazmente para confirmar aquello que ya se había anticipado: esa tierra no ofrece posibilidades de trabajo y por ende el hombre debe partir. Acto seguido la familia abandona su rancho para buscar un empleo en el Ingenio de Campos Aguirre. Estas cualidades propias del cine directo como la observación de otras realidades y el acercamiento a sujetos populares se combinan con el impulso referencial, la presencia de los niños y la espontaneidad de las tomas en esas miradas a cámara de los pobladores que son desinfectados al llegar; rasgos provenientes del neorrealismo italiano. De este modo, previamente a que la familia aborde el tren que la llevaría a su destino, se produce un gesto que combina la modernidad de las formas expresivas y el sentimentalismo del neorrealismo. "El hijo de la familia se desprende de su perro y la subjetividad del personaje se inscribe en la imagen: de un primer plano de su rostro nos transportamos a una imagen mental donde por medio de un efecto de agua visualizamos al niño y al perro

las Artes junto con el Instituto Cinefotográfico de la Universidad Nacional de Tucumán, bajo la dirección de Jorge Prelorán. Este programa consistía en "viajar por las regiones del centro y noroeste para documentar una serie de eventos de tenor folklórico y rescatar así cosas auténticamente argentinas para mostrar a los demás argentinos" (Rossi, 1987, p. 22). 
jugando a orillas de un río” (Cossalter, 2017a, p. 17). El corto concluye con la mirada a cámara del niño mientras el tren se aleja de la estación.

En definitiva, Tierra seca rescata la identidad de una familia y una comunidad norteña para marcar el desequilibrio y la desigualdad. O quizás es al revés, y esta inestabilidad es la base para poner en valor a la comunidad. De todas formas, el postulado de crítica social es el que guía el relato, aunque este mantiene un carácter distanciado. No obstante, el distanciamiento del sujeto enunciador para con la entrega del mensaje y la cámara que pretende una observación no intrusiva terminan por contraponerse al sentimentalismo y la subjetividad que ofrecen los sujetos captados. Si bien el título del film haría alusión a un problema de la naturaleza, la inscripción inicial acerca del éxodo obligado por la miseria refleja esta ambigüedad entre la mera observación retirada y el compromiso social; entre el cine como registro y en tanto dispositivo que apela a la emoción para aprehender al receptor.

Ceramiqueros de Traslasierra (Raymundo Gleyzer, 1965) fue concebido en el Departamento de Cine de la escuela de Artes de la Universidad Nacional de Córdoba y al igual que Tierra seca este apela a la observación de la cámara, aunque aquí es el testimonio el recurso principal que estructura el relato. En esta oportunidad el espacio geográfico abordado es la provincia de Córdoba, en los alrededores de Mina Clavero, y el foco está puesto en una pequeña comunidad de alfareros de la cual Alcira López es su personaje protagónico y quien se convierte en el centro de atención del film. Una cámara descriptiva al inicio, que nos sitúa en el espacio concreto y que retrata a sus habitantes, se entrelaza con el juego de múltiples voces, las cuales denotan diversos grados de objetividad/subjetividad: una voz over narradora que, de forma intermitente, repone información al espectador; las preguntas en off de la antropóloga y guionista del film, Ana Montes de González, que marcan el enfoque socio-político del cortometraje y los testimonios de Alcira sobre el desarrollo de la alfarería y las condiciones de vida que tienen su correlato en la banda de imagen a través del registro de los lugareños en pleno ejercicio del oficio. Justamente la interacción entre la antropóloga y Alcira resulta 
interesante básicamente por el tenor de las preguntas que apuntan a comprender el modo y la calidad de vida:

-Ana: ¿Se siente feliz cuando trabaja?

-Alcira: ¿'Tengo que decirlo ahora? Y sí.

Ahora bien, esta propuesta trasciende el mero registro y la constatación de una realidad para formular una crítica social manifiesta, que se apoya tanto en la palabra como en la imagen. Por un lado, la conciencia socio-política se disemina en una estructura narrativa y enunciativa autoconsciente: se incorporan intertítulos con los nombres de los lugareños mientras que son mostrados en sus acciones cotidianas; una cámara autónoma recorre la comunidad, contempla a los niños trabajando al tiempo que miran a cámara -interpelación al espectador- $\mathrm{y}$ focaliza mediante primeros planos en las manos de los alfareros y los objetos que producen -en tanto gestus social que visibiliza la tensión entre lo artesanal y lo precario-; se explicita el artificio y la autorreflexión a partir de la inserción de dos fotografías del equipo de rodaje dentro de la comunidad. Por el otro, la antropóloga se transforma en la portavoz del discurso crítico puesto que comienza preguntándole a Alcira si les alcanza para vivir y concluye el film con el interrogante acerca de si piensa que con esta película van a poder ayudarla, a lo que ella responde que tal vez, pero que hasta ahora nadie los ha ayudado. Si bien la autoridad textual del film no se desplaza por completo al testimoniante, la interacción entre el sujeto enunciador y el sujeto filmado, junto a la estructura autoconsciente y reflexiva, se orientan pura y exclusivamente en función del entrevistado.

En resumen, Ceramiqueros de Traslasierra exhibe un compromiso político bien marcado, aunque uno de los propósitos sigue siendo el de registrar la vida de un sujeto o una comunidad marginada y ponerla al descubierto ${ }^{13}$. En este sentido, el film no postula una mirada distante sobre los hechos sino que se involucra completamente en la crítica a la falta de apoyo que esta comunidad regional y marginal sufre.

13 Dicha actitud se condice con una de las cuatro tendencias fundamentales de la poética documental según Michael Renov: registrar, mostrar o preservar. Véase: Renov (1993). 
En Brasil, la renovación cinematográfica de la época se materializó en el Cinema novo, movimiento de ruptura frente al modelo industrial de Hollywood dotado de una conciencia social y un espíritu testimonial14. Pese a destacarse por la producción de largometrajes de ficción, la presencia de cortos documentales fue fundamental, sobre todo inicialmente en relación a la reflexión sobre la identidad cinematográfica nacional y la revalorización de tradiciones marginadas. Si bien los límites temporales del Cinema novo son un tanto difusos, con un claro desarrollo en los años sesenta y principios de los setenta, cierto consenso señala al film Río, 4 o grados (Nelson Pereira dos Santos, 1955) en tanto precursor y a Barravento (Glauber Rocha, 1962) como el origen. No obstante, Silvana Flores (2013) complejiza el análisis de este fenómeno estético y político heterogéneo postulando una periodización abarcadora y al mismo tiempo particularizada. La autora piensa una primera fase neorrealista (1955-1961) -que entiende al cine como vehículo de denuncia social-, una segunda etapa etiquetada como el ciclo del Nordeste (1961-1964) -con el sertão como símbolo de miseria y hambre-, una tercera conocida como el ciclo Urbano (1964-1968) -que incentiva la toma de posición de la sociedad para con el golpe de Estado cívico-militar- y una última etapa Tropicalista (1968-1972) - un cine de resistencia en conexión con el modernismo brasileño-. En cuanto a los medios y las entidades de producción, hasta el golpe de Estado de 1964 el ámbito universitario tuvo un rol destacado, tanto en los debates iniciales como en la gestación de un cine político y estéticamente revolucionario. El Centro Popular de Cultura de la Unión Nacional de Estudiantes de Río de Janeiro, junto a sus centros satélites en otras ciudades, fue uno de los más relevantes. Luego, pequeñas productoras independientes, autoproducciones y hasta incluso el recurso del encargo en pos de plantear perspectivas políticas autónomas completan el abanico de variantes para financiar estas obras modernas y críticas ${ }^{15}$.

14 Para profundizar de forma exhaustiva en esta corriente fílmica se recomienda la lectura de Amar Rodríguez (1994) y Xavier (2001).

15 Nuevamente, el análisis propuesto podría ponerse en práctica en derredor a un corpus de cortos más extenso. Citamos algunos títulos como: O poeta do Castelo (Joaquim Pedro de Andrade, 1959), O mestre de Apipucos (Joaquim Pedro de Andrade, 1959), Aruanda (Linduarte Noronha, 1960), Un dia na rampa (Luiz Paulino dos Santos, 1960), Maioria Absoluta (Leon Hirszman, 1964), Integração Racial (Paulo César Saraceni, 1964), O Circo 
Arraial do Cabo (Mário Carneiro y Paulo César Saraceni, 1959), producido por la pequeña compañía Saga Filmes, retrata las condiciones de vida de los pescadores del pueblo de Arraial do Cabo, ubicado en el litoral de Río de Janeiro. Encuadrado dentro de la etapa neorrealista del Cinema novo, este corto combina elementos de dicha corriente italiana junto con la presencia marcada del encuadre y del montaje, conformando en algunos pasajes un entramado visual y conceptual de corte poético. Ahora bien, la postura de registro que la cámara adopta a lo largo del relato suscita, de forma soslayada, una perspectiva crítica reforzada nítidamente por una voz over narradora intermitente. De este modo podemos corroborar que el arribo de la Fábrica de Álcalis instala un proceso de industrialización en la zona que desestabiliza el tipo de producción manual y artesanal del pescador, empujando a este al éxodo. Las diversas secuencias que estructuran el film se sostienen fundamentalmente en la observación de los pescadores en plena jornada de trabajo y sus diferentes etapas. A esto se suma el retrato de los niños, las mujeres y los pescadores junto a los operarios al finalizar el día; imágenes tamizadas por una exacerbada emotividad y sentimentalismo al estilo neorrealista: cámara baja para acercarse a los niños, primerísimos planos de las manos de las mujeres salando el pescado, largos primeros planos de los rostros de los trabajadores durante el descanso. Por otra parte, resulta medular el papel que ejerce el montaje, tanto en un nivel estético como conceptual y político. Este procedimiento no sólo contrapone el universo de la pesca con el mundo de la maquinaria y la industria, sino que también opera al interior de cada terreno, exhibiendo un grado de autoconciencia enunciativa que puede pensarse en correlato con una conciencia social. Por un lado, señalamos el montaje rítmico en un espacio abierto e iluminado que repara en el acto de pescar. Por el otro, hacemos mención a una serie de encuadres en picado y contrapicado de los operarios industriales mirando a cámara en el espacio cerrado y oscuro de las maquinarias. 
En consecuencia, a partir de la composición plástica y visual de la imagen queda asentado el enfoque revalorizador del pescador que el cortometraje manifiesta mediante la presencia de una cámara observadora. No obstante, es también desde la imagen, con apoyo de la palabra, que el film postula su crítica y concientización en torno a una industrialización no controlada. La Fábrica de Álcalis no sólo promueve el alejamiento del pescador sin recursos, sino que también resulta una amenaza para aquellos que aún resisten, puesto que sus desechos tóxicos contaminan las aguas afectando directamente el trabajo y la vida de los residentes.

El caso de Maranhão '66 (Glauber Rocha, 1966) es bastante particular, puesto que si bien fue concebido a través de las productoras independientes Mapa Filmes ${ }^{16}$ y Produções Cinematográficas L.C. Barreto, este corto surgió como un encargo que el reciente gobernador electo José Sarney le había hecho a Glauber Rocha. No obstante, a pesar de haber sido originalmente pensado como un film de propaganda, el resultado distó mucho del gesto complaciente que dicha figura política, colaboradora activa de la dictadura, esperaba. Por medio de cualidades observacionales, el testimonio directo y un montaje en contrapunto el film breve devela la miseria y el hambre que azotaban la región. En este sentido, es posible considerarlo en tanto una obra bisagra entre el ciclo del Nordeste, ya que vislumbra las problemáticas del territorio, y el ciclo Urbano, promoviendo un claro posicionamiento frente al Golpe de Estado acaecido poco tiempo atrás. El relato toma como eje rector la ceremonia y el discurso de asunción de Sarney, en un primer instante, desde una perspectiva cercana al cine directo que registra una situación: cámara en mano espontánea y movediza alrededor de la llegada del político, panorámica a la multitud, sonido ambiente y cánticos del público presente ${ }^{17}$. Sin embargo, las palabras del gobernador son rápidamente disociadas de su fuente de origen para ser confrontadas con la cruda realidad que Rocha elige mostrar en un tono observacional, por medio de una cámara autónoma que descubre la pobreza, el hacinamiento y la injusticia. El contrapunto entre las

\footnotetext{
${ }^{16}$ Esta compañía fue fundada en los años sesenta por Zelito Vianna, Glauber Rocha y Walter Lima Jr., entre otros.

17 Este es el primer film de Rocha grabado con sonido directo.
} 
promesas demagógicas de campaña y la realidad social del nordeste es directo y contundente. Mientras que Sarney habla de "la libertad de elegir y preferir, de la conciencia de las opciones" vemos un rancho precario y una familia con niños desnutridos. Cuando este se pronuncia sobre las "altas tasas de mortalidad infantil” la cámara se acerca a niños y jóvenes enfermos de tuberculosis. En este momento dos testimonios que apoyan la postura crítica del film irrumpen ante el ojo de la cámara: un joven que no tiene recursos ni esperanzas para afrontar la enfermedad y dos médicas que denuncian la falta de pago por su trabajo. Luego, un basural con familias enteras se carga de sentido al tiempo que oímos la enfática afirmación de que dicho Estado tiene "una reserva humana muy grande". Por último, el cortometraje culmina con la finalización del discurso y un paneo de cámara sobre la gente en la miseria.

Al fin y al cabo, las palabras de Sarney sirven como puntapié para retratar las paupérrimas condiciones de vida y de trabajo en la región del nordeste del Brasil, así como también su contrapunto pretende generar una conciencia acerca del contraste entre la retórica política y la realidad social. Estimular una conciencia nacional en el pueblo, objetivo que este corto ostenta, era uno de los propósitos centrales perseguidos por el Centro Popular de Cultura, entidad en donde Rocha había colocado el germen de un arte verdaderamente revolucionario.

Finalmente, en México, al igual que en Argentina, y en menor medida Brasil, el terreno universitario fue el espacio medular para la modernización cinematográfica y el compromiso social; este último con mayor impacto especialmente luego de la radicalización política alrededor del Movimiento del 68. Como parte de la Dirección de Difusión Cultural de la Universidad Nacional Autónoma de México se creó el Departamento de cine en el año 1959 y la Filmoteca -conocida como Filmoteca de la UNAM- en 1960. Ya para 1963 se fundó el Centro Universitario de Estudios Cinematográficos (CUEC), otro de los pilares de la renovación en el campo fílmico. Este, junto con el grupo Nuevo Cine, incentivaría la realización del I Concurso de Cine 
Experimental en 1964 en el cual participarían varios directores emergentes ${ }^{18}$. Dentro de esta órbita, el cortometraje documental y experimental se erigió como el medio privilegiado para retratar el arte y la cultura local recuperando tradiciones del pasado y ocupándose de las vicisitudes contemporáneas-, al tiempo que intentó desempeñarse como un dispositivo de concientización y transformación política en derredor a los conflictos sociales en ascenso hacia finales de década. Posteriormente, la renovación continuaría con la formación de los grupos Cine 70 y Cine independiente, y del Centro de Producción de Cortometrajes (CPC) ${ }^{19}$.

Mural efímero (Raúl Kamffer, 1968) fue producido por la Dirección General de Difusión Cultural de la UNAM. Este corto registra el proceso de construcción del evento contracultural performático que lleva su mismo nombre. Como respuesta a la violenta represión que sufría el movimiento estudiantil y que poco tiempo después culminaría en la denominada Masacre de Tlatelolco el 2 de octubre de 1968, un grupo de entre cincuenta y sesenta artistas plásticos decidió levantar un mural emplazado en las láminas acanaladas de doce metros de alto que cubrían la damnificada estatua de Miguel Alemán, ubicada en la Ciudad Universitaria. Se trató de una creación colectiva, efectuada con fondos de donativos personales, en el que artistas muy diversos se reunieron con un objetivo común: respaldar al movimiento estudiantil y visibilizar la conducta autoritaria del presidente Gustavo Díaz Ordaz mediante una intervención artística comprometida. El film, de apenas diez minutos de duración y realizado en color, pone en escena de manera sintética el desarrollo de dicho acontecimiento a partir de un enfoque observacional y un montaje dinámico con encuadres que evidencian múltiples puntos de vista en torno al mural, en sintonía con la banda sonora

18 Dicho concurso fue en realidad convocado por el Sindicato de Trabajadores de la Producción Cinematográfica (STPC) al interior de la esfera profesional. Para ahondar en este período dentro de la cinematografía mexicana, véase: AA.VV. (1988) y Rodríguez (2014).

19 A diferencia de los casos argentino y brasileño, en México los cortometrajes de impronta social anteriores a 1968 no se abocan a problemas acaecidos en el presente de su concepción, requisito necesario para nuestra propuesta de reflexión patrimonial. En la década del setenta el Centro de Producción de Cortometrajes realizó innumerables cortos socio-políticos anclados en el contexto de producción. Por otro lado, uno de los pocos films breves que podría acompañar en esta senda al único ejemplo mexicano contemplado es Los estudiantes, la Universidad y la violencia (Manuel González Casanova, 1968). Sin embargo, este se encuentra inconcluso. 
que articula una música de rock -la banda Deep Purple- y textos poéticos pronunciados por una voz over que marcan la perspectiva política del documental: "Quisimos hacer hablar los muros, llenar el silencio"; "La juventud combatió, se enterró sin flores y aún muerta fue violada”. La cámara no sólo contempla el acto creativo y el producto concluido, mediante un recorrido que focaliza en los diferentes fragmentos de la obra, sino que también repara, con la misma postura, en el evento que engloba al hecho artístico y que incluye mesas populares de libros, discursos y bandas en vivo. El cortometraje concluye con un collage experimental de fotografías superpuestas de los jóvenes muertos y de uno de los principales responsables de la masacre: el General y Jefe del Departamento del Distrito Federal Alfonso Corona del Rosal.

En suma, la plena voluntad de registro del acto contracultural global que el film manifiesta al retratar la construcción del mural y del evento que lo enmarca es trascendida por otros objetivos concretos que forman parte de la práctica política. En principio, el registro tiene como propósito su difusión, y en este caso conlleva el deseo de informar, o mejor dicho, contrainformar; romper el cerco informativo. Es decir, divulgar el apoyo al movimiento estudiantil y sacar a la luz la verdad de los hechos. Esto se refuerza con la inserción de las fotografías al final del cortometraje. Asimismo, la narración poética le añade a dicha misión una voluntad de concientización, acentuando el marcado compromiso social que presenta el film.

\section{El cortometraje documental latinoamericano: construcción de memoria y puesta en valor patrimonial}

Desde una concepción general, toda imagen puede tornarse un documento histórico (Burke, 2005) si se la apropia no como fuente sino en tanto vestigio del pasado en el presente, es decir, como testimonio. En este sentido, las imágenes condensan en sí mismas su propio contexto social y es desde la recepción que puede activarse su potencia como documento. Sin embargo, a los fines de nuestro trabajo, lo interesante reside en aquellos casos donde la voluntad por transformar la imagen en un documento para la posteridad 
subyace en la instancia de producción, en estrecha combinación con otros objetivos más bien inmediatos. El corpus de cortometrajes documentales latinoamericanos modernos abordado en este artículo no sólo emprende el registro contemporáneo de acontecimientos conflictivos, situaciones marginales y eventos contraculturales para intervenir como agente en dicha realidad social, sino que al mismo tiempo y de acuerdo a diversos grados de conciencia termina por construir un patrimonio del presente (Colin, 2014) ${ }^{20}$. Del mismo modo que la noción de patrimonio no comporta de forma excluyente y obligada una estricta relación con el pasado, y por ende puede manifestarse como una anticipación patrimonial (Colin, 2014) ${ }^{21}$, la memoria tampoco es un concepto que sólo debe pensarse en un vínculo con el tiempo pretérito. La memoria, entendida como trabajo (Jelin, 2002) -es decir, proceso antes que producto-, se erige en tanto acto constructivo. De esta forma, el audiovisual, debido a su plena capacidad de registro visual y sonoro de la realidad, se vislumbra como un vehículo efectivo de construcción de memoria(s) social(es) y cultural(es). En palabras de Carmen Guarini, "pensamos que la acción misma de registrar elementos de un presente forma parte del trabajo de construcción de la memoria social, ya que la elaboración de registros audiovisuales no es un acto mecánico sino una empresa llevada adelante por sujetos sociales históricos que inciden subjetivamente en su producción” (2002, p. 116).

Ahora bien, la articulación de la memoria y el pasado es, claramente, una tendencia productiva en el ámbito cinematográfico. De este modo, “oscilando entre estos dos polos de la elaboración de la memoria, el que pone el acento en el pasado (y su 'peso' sobre el presente) y el que enfatiza el presente (y su actividad de 'construcción'), se ubican las imágenes fotográficas y fílmicas" (Feld \& Stites Mor, 2009, p. 26). Cierto documental socio-político suele postularse como fuente activadora de la memoria, recuperando hechos del pasado para reflexionar, en definitiva, sobre el presente. No obstante, los

${ }^{20}$ Se trata de "un objeto que no tiene fundación y legitimidad histórica para transformarse oficialmente en patrimonio" (Colin, 2014, p. 6).

${ }^{21}$ Esta consiste en "la pre-fundación de la patrimonialización de un objeto que se basa en los valores que la gente atribuye a este objeto" (Ibídem), el cual puede ser legitimado o no de forma oficial con posterioridad. 
cortos documentales aquí apuntados y analizados no recurren al pasado para entender el presente. Por el contrario, se abocan al presente para actuar en ese tiempo y construir un documento que sostenga la memoria en el futuro. En otros términos, dicha producción se refiere a un pasado próximo (Lara López, 2005) o, en todo caso, edifica una memoria del presente. Así pues, nuestro corpus evidencia una doble función mnemónica: vehículo de construcción y soporte de conservación. Para poder ahondar en tales disposiciones es preciso no sólo examinar algunas cualidades textuales de los films en cuestión, sino por sobre todo explorar las condiciones y las entidades de producción en las que estos se insertan.

En principio, la decisión de configurar un relato sustentado en una cámara que registra imágenes de no ficción en el presente de su concepción conlleva, de por sí, un carácter documental en sentido amplio, brindando el marco propicio para la construcción mnemónica. En Tierra seca, la leyenda inicial que anticipa aquello que el film ofrecerá en imágenes al tiempo que establece el enfoque crítico frente a la miseria que sufren los habitantes de dicha comunidad forzados al éxodo culmina con un gesto de conciencia acerca del poder de lo visual: "este es el prólogo a la historia que hoy están haciendo". Es decir que el film se erige como un documento que pretende establecer un cimiento inicial para la factura de una memoria del presente en torno a una identidad regional y marginal. En este sentido, memoria e identidad se funden en un vínculo procesual y dinámico anclado en el retrato audiovisual de un pueblo segregado. Ceramiqueros de Traslasierra añade a la observación revalorizadora de una comunidad marginada el testimonio como motor de identidad en el marco de una estructura enunciativa que explicita su carácter de denuncia y manifiesta una conciencia acerca del valor mnemónico que dicha producción visual y sonora puede adquirir y portar. La actitud activa de la antropóloga y guionista Ana Montes de González y la participación efectiva del equipo de rodaje en la comunidad denotan un enfoque etnográfico en donde "el cine se presta naturalmente como un instrumento de documentación del comportamiento humano (Jorge Prelorán 
citado en Rossi, 1987, p. 86). Documento y memoria se combinan en el registro pormenorizado del oficio alfarero.

Esta conciencia en el valor documental que exhiben los ejemplos argentinos se encuentra estrechamente relacionada con su ámbito de producción. Por un lado, el Fondo Nacional de las Artes dispuso un Régimen de Fomento al Cine de Cortometraje para financiar, entre otras cosas, films destinados a difundir el folclore argentino y documentar el desarrollo de actividades culturales. Ahora bien, el Fondo no sólo estimulaba la producción de los cortos sino que se encargaba asimismo de la difusión. Para ello, la entidad tenía la facultad de adquirir una copia de los cortos subsidiados bajo este régimen. De este modo, la conformación de una cineteca tendiente a divulgar las obras marca tanto la concepción patrimonial que el Fondo le otorgaba a estos cortos como también la conciencia en la preservación de dicha producción, y por ende, su potencialidad mnemónica. Por otro lado, el Departamento de Cine de la escuela de Artes de la Universidad Nacional de Córdoba no sólo había configurado una carrera de cine, sino que al mismo tiempo constituyó un Centro de Producción y un Centro de Extensión y Difusión para contener y exhibir los cortos realizados. Asimismo, se establecieron convenios con el FNA y otras universidades para producir cortos documentales de índole social y folclórica, evidenciando una perspectiva compartida en torno al carácter patrimonial y documental de los films concebidos durante este período.

A diferencia de Argentina, en Brasil las empresas productoras de los films analizados no traslucen un compromiso directo en la construcción mnemónica y la puesta en valor patrimonial. Dicha voluntad de documentación surge como una propuesta estrictamente autoral ${ }^{22}$. Sin

${ }_{22} \mathrm{El}$ proyecto conocido como Caravana Farkas, llevado a cabo por el productor de origen húngaro Thomas Farkas, fue una de las excepciones. El mismo consistió en dos etapas. En la primera se realizaron una serie de cortos/mediometrajes documentales entre 1964 y 1965 a modo de caravana a través del nordeste brasileño con el objeto de registrar las problemáticas sociales de la región. Allí participaron los cineastas Paulo Gil Soares, Manuel Horácio Giménez, Maurice Capovilla y Geraldo Sarno. Estas obras formaron parte de la compilación Brasil verdade (1968). Luego, junto con Edgardo Pallero, Farkas produjo diecinueve cortometrajes de la misma índole reunidos en A condição brasileira (1970). En este caso los directores involucrados fueron Sérgio Muniz, Geraldo Sarno, Eduardo Escorel y Paulo Gil Soares. Para profundizar en la temática, véase: D’Almedia (2002) y Flores (2013). 
embargo, dos entidades locales manifestaron en esta época el afán por acoger y difundir obras que retrataran la realidad social: el ya mencionado Centro Popular de Cultura de la UNE y la Cinemateca Brasilera. En cuanto al primero, y en su deseo de llevar el arte al pueblo, este contó desde su creación con un ala volante destinada a difundir las obras de teatro y los films en espacios no tradicionales como universidades y sindicatos, ubicados especialmente en los márgenes de las grandes ciudades. Esta función desembocó asimismo en un estímulo a la producción de films documentales en $16 \mathrm{~mm}$. en diferentes regiones del país. En relación a la segunda, la Cinemateca desempeñó la tarea de conservar y divulgar los films nacionales, confiriéndoles una entidad patrimonial. Por ejemplo, en el año 1961, junto a su conversión en fundación -hecho que le permitía un mayor despliegue institucional-, esta promovió la exhibición de una serie de cortometrajes de carácter social en la VI Bienal de San Pablo. Entre ellos se encontraba Arraial do $\mathrm{Cabo}^{23}$. A su vez, dicho organismo se encargó de la recuperación del cortometraje Maranhão '66, obra que había soportado la censura federal y restricciones para su distribución en años de la dictadura.

Arraial do Cabo sostiene a través del montaje y una cámara observadora la crítica al proceso de industrialización descontrolado que sufría el pueblo, aunque al mismo tiempo construye un documento que retrata la vida de esta comunidad de pescadores con la cual el equipo de rodaje convivió durante algunos meses. Son las formas tradicionales del proceso de la pesca, dotadas de un sentido ambiguo entre lo artesanal y lo precario, aquello que el film pretende resguardar como parte del legado de un modo de vida autóctono que estaba desapareciendo. Esta premisa es reforzada nítidamente por la voz over narradora cuando expresa que "los pescadores se alejan hacia playas más distantes cargando con la memoria de Arraial”. Memoria que este corto intenta plasmar en imágenes y que se halla en sintonía con dos postulados del cine de esta época: la valorización de lo nacional mediante un sentido crítico que Glauber Rocha reconocía de forma inaugural en este film (Sadoul, 1972); y la famosa frase pronunciada por Paulo Cesar Saraceni luego

23 Posiblemente este acto de visibilización le haya permitido al film la posterior circulación y premiación que tuvo en festivales internacionales de España, Italia y Francia. 
popularizada por Rocha, "una idea en la cabeza, una cámara en la mano", que denota una voluntad de compromiso y autenticidad. Maranhão '66 se conformó directamente como un documento con valor histórico para la posteridad puesto que, trastocando el propósito inicial del encargo, Rocha decidió registrar en imágenes la miseria que azotaba la región por aquel entonces. De esta forma, el audiovisual se postula como un vehículo de construcción y soporte de la memoria social; memoria visual y sonora en torno a una profunda problemática anclada históricamente en dicha región. Como bien señala Luiz Santiago: "Para a realidade de um Brasil que ainda luta contra a miséria, Maranhão 66 é um pedaço de memória viva, algo que devemos olhar e chegar à conclusão de que aquilo pelo que hoje lutamos para que o nossa realidade seja melhor já era alvo de discussão em pauta há muito tempo" (2014) ${ }^{24}$. Asimismo, el carácter consciente del film en tanto documento puede también comprobarse posteriormente, ya que el mismo fue concebido por Rocha como base para la confección de su largometraje Terra em transe (1967).

Por último, México contaba en este período con una de las instituciones más destacadas en términos de conciencia del patrimonio audiovisual a nivel regional: la Filmoteca de la UNAM fundada en 1960²5. Para 1963 su acervo llegaba a los ciento treinta y siete films, y cuatro años más tarde disponía ya de trescientas obras. Ahora bien, no sólo funcionaba como un espacio de guarda, sino que en conjunto con el CUEC y la Dirección General de Difusión Cultural -bajo el auspicio constante de la Universidad- se encargó de estimular la producción y divulgar las películas a través de festivales, cineclubes y programas televisivos ${ }^{26}$. Allí, el cortometraje documental predominó por sobre las demás tipologías fílmicas. Quizás, esta

24 "Para la realidad de un Brasil que todavía lucha contra la pobreza, Maranhão 66 es un recuerdo vivo, algo que debemos mirar y llegar a la conclusión de que aquello por lo que hoy luchamos para que nuestra realidad sea mejor ya había estado en la agenda de discusión durante mucho tiempo" (Traducción del autor).

${ }_{25}$ La Filmoteca fue la principal promotora para la creación de la Unión de Cinematecas de América Latina (UCAL) en 1965.

${ }^{26}$ En las memorias publicadas en la página web de la institución sobresale, en esta fase, la concreción del Festival Cinematográfico Universitario de la Asociación de Cine Experimental y del Festival de Cine Mexicano en París, la puesta en marcha del Cine Club Fellini y del Cine Club Infantil, así como la organización del programa televisivo "El cortometraje en el mundo". 
consideración patrimonial junto con el refuerzo de una entidad alternativa de producción como la universitaria llevara a priorizar el carácter de documentación del dispositivo cinematográfico. Al igual que el Fondo Nacional de las Artes en Argentina, el trabajo de preservación que realizó la Filmoteca a lo largo de las décadas es el que nos permite hoy en día acceder a la mayoría de los cortometrajes documentales de esta etapa que, desde hace algunos años, la entidad ha comenzado a digitalizar y colocar en línea para su acceso gratuito.

Mural efímero consuma un registro audiovisual del evento contracultural homónimo, en donde el acto central está constituido por la elaboración colectiva de un mural en apoyo al movimiento estudiantil. La función contrainformativa y de denuncia es inseparable, en este caso, de su pretensión de documentación y construcción mnemónica. El asentamiento en imágenes de un acontecimiento pensado como circunstancial y volátil que podría resultar al menos paradójico- guarda en sí mismo un gesto consciente de adjudicación patrimonial y un deseo por conformar una memoria visual de este acto social para la posteridad. De hecho, este film fue realizado en color, algo poco común en la época para una producción de bajo presupuesto concebida sobre la inmediatez de los sucesos. Al tratarse de un mural pictórico, el registro del color es una variable imprescindible para documentar de la forma más fiel posible dicha obra paradigmática. Finalmente, es gracias a esta intención de conservar en imágenes un evento efímero de importancia histórico-cultural que pudo reflexionarse ulteriormente de manera pormenorizada y auténtica sobre las implicancias artísticas y políticas del hecho acaecido. Cabe destacar que en el año 2008 María Judith Alanís Figueroa realizó el documental Trazos en Trozos: Mural Efímero, México 68, el cual articula testimonios de los artistas que participaron en el mural, historiadores del arte que analizan la época y fragmentos del cortometraje de Kamffer. Allí, el cineasta Federico Weingartshofer resume la concepción del cine que adoptó Mural efímero y la que sostiene, a fin de cuentas, el corpus analizado en este trabajo: "el cine tiene fines de registro y de trascender al tiempo, y de servir de testimonio”. 


\section{Reflexión final}

A lo largo del presente trabajo hemos tratado de asentar, a través del análisis de un grupo específico de films y sus condiciones de producción, la articulación productiva que durante la modernidad cinematográfica se estableció en Latinoamérica entre el cortometraje y el documental alrededor de una tendencia de cine social. Ahora bien, las potencialidades del corto en su vínculo con el modelo documental, las innovaciones tecnológicas de la época y las apropiaciones de corrientes foráneas innovadoras no sólo posibilitaron el registro de comunidades marginadas y conflictos socioculturales en pos de intervenir sobre dicha realidad inmediata, sino que al mismo tiempo dinamizaron la capacidad del cine para construir memoria(s). Es decir que el film breve se convirtió en un dispositivo eficaz de aprehensión y agente de la historia dentro de su propio contexto de acción, al tiempo que llevó a cabo un proceso de patrimonialización cultural sobre esa misma realidad retratada. Es principalmente entonces el carácter observacional de la cámara, sustentado en la conciencia sobre el potencial mnemónico del medio audiovisual, aquello que conecta entre sí un registro para el presente y un documento para el futuro. En suma, registro y dispositivo, documento y memoria aparecen en este corpus de cortometrajes documentales latinoamericanos modernos como caras de una misma moneda. Ahora bien, la reflexión acerca de la construcción mnemónica que este corpus suscitó y evidenció implicaría de forma imperiosa estudiar la puesta en valor actual de tales documentos, tarea tenuemente esbozada en algunas líneas de este artículo que con seguridad será profundizada en próximos trabajos.

\section{Referencias bibliográficas}

Amar Rodríguez, V.M. (1994). El cine nuevo brasileño (1954-1974). Madrid: Dykinson.

AA.VV. (1988). Testimonios y documentos del nuevo cine latinoamericano, Vol. II. México. México: Fundación Mexicana de Cineastas, AC.

Baudry, J.L. (1975). Le dispositif: Approche métapsychologique de l'impression de réalité. Communication. 23 (1), 56-72. 
Benet, V. (2008). Otros modelos cinematográficos. La cultura del cine: introducción a la historia y la estética del cine (pp. 139-153). Barcelona: Paidós.

Bergese, M., Pozzi, I. \& Ruiz, M. (1997). Anatomía de cuerpos menudos. Sobre el pasado y el presente del cortometraje nacional. Ossessione, 1 (1), 65-66.

Bordwell, D. (1996). La narración en el cine de ficción. Madrid: Paidós.

Burke, P. (2005). Visto y no visto. El uso de la imagen como documento histórico. Barcelona: Editorial Crítica.

Colin, C. (2014). Patrimonio del presente: fundamentos y límites. La noción de patrimonio en Ciencias Sociales: controversias, usos y abusos. Santiago: Universidad de Chile.

Cossalter, J. (2015). Renovación estética e instrumentalización política radical. El cortometraje moderno en Argentina (1955-1976). Questión. Revista Especializada en Periodismo y Comunicación. 1 (47), 309324 .

Cossalter, J. (2017a). El Fondo Nacional de las Artes y el cortometraje argentino. Modernización cultural y estética. Sociohistórica. 40 (35).

Cossalter, J. (2017b). Experimentación e innovación en el cortometraje documental latinoamericano moderno: las experiencias de Brasil, Cuba y México. Kamchatka. Revista de análisis cultural. 10, 489-511.

Cossalter, J. (2018a). El cortometraje latinoamericano moderno. Experimentación estética y vínculos con el campo cultural en Argentina, Cuba y México. Anales del Instituto de Investigaciones Estéticas. 40 (113), 9-39.

Cossalter, J. (2018b). La figuración del niño en el cortometraje documental social y político argentino de los años sesenta y setenta. Studies in Spanish \& Latin American Cinemas. 15 (1), 83-101.

Cossalter, J. (2019). El cortometraje como impulsor primigenio de la modernidad cinematográfica en Brasil y en Chile. Entre la pesquisa estética y el compromiso social. Meridional. Revista Chilena de Estudios Latinoamericanos. 12, 17-54.

D'Almeida, A. D. (2002). Caravana Farkas: uma simbiose entre cinema documentário e folkcomunicação. Idade Mídia: Revista da Faculdade de Comunicação Social/Fiam-Faam. 1 (2), 57-66.

Dittus Benavente, R. (2012). El cine documental político y la noción de dispositivo. Una aproximación semiótica, Tesis. Bellaterra: Universitat Autónoma de Barcelona.

Feld, C. \& Stites Mor, J. (2009). El pasado que miramos. Memoria e imagen ante la historia reciente. Buenos Aires: Paidós.

Ferro, M. (1980). Cine e Historia. Barcelona: Editorial Gustavo Gili, S.A. 
Flores, S. (2013). El Nuevo Cine Latinoamericano y su dimensión continental. Regionalismo e integración cinematográfica. Buenos Aires: Imago Mundi.

Gilman, C. (2003). Entre la pluma y el fusil. Debates y dilemas del escritor revolucionario en América latina. Buenos Aires: Siglo Veintiuno Editores Argentina.

Guarini, C. (2002). Memoria social e imagen. Cuadernos de Antropología Social. 15, 133-123.

http://revistascientificas.filo.uba.ar/index.php/CAS/article/view/462 $\underline{\mathrm{O}}$

Jelin, E. (2002). Memorias de la represión. Los trabajos de la memoria. Madrid: Siglo XXI Editores de España S.A.

Lara López, E. L. (2005). La fotografía como documento histórico-artístico y etnográfico: una epistemología. Revista de Antropología Experimental, 5 .

https://revistaselectronicas.ujaen.es/index.php/rae/article/view/206 $\underline{8}$

Meier, A. (2013). El cortometraje: el arte de narrar, emocionar y significar. México: Universidad Autónoma Metropolitana-Xochimilco.

Mestman, M. (2010). Testimonios obreros, imágenes de protesta. El directo en la encrucijada del cine militante argentino. Cine Documental, 2.

http://revista.cinedocumental.com.ar/2/articulos_01.html

Mestman, M.(Coord.) (2016). Rupturas del 68 en el cine de América Latina. Buenos Aires: Ediciones Akal, S.A.

Paranaguá, P. A. (2003). Tradición y modernidad en el cine de América Latina. Madrid: FCE.

Pécora, P. (2008). Algunas reflexiones sobre el cortometraje. En E. Russo (Comp.), Hacer Cine: Producción audiovisual en América Latina (pp. 377-387). Buenos Aires: Paidós.

Plantinga, C. (1997). Rhetoric And Representation In Nonfiction Film. Cambridge: Cambridge University Press (trad esp. Retórica y representación en el cine de no ficción. México: Universidad Autónoma de México, 2014).

Pick, Z. (1993). The New Latin American Cinema. A Continental Project. Austin: University of Texas Press.

Renov, M. (1993). Toward a Poetics of Documentary. Theorizing Documentary. New York: Routledge (trad esp. Hacia una poética del documental. Cine Documental, 2010, 1).

Rodríguez, I. (2014). Un cine de autor para México. En R. Eder (Ed.), Desafío a la estabilidad. Procesos artísticos en México 1952-1967. México: UNAM/Turner. 
Rossi, J. J. (Comp.) (1987). El cine documental etnobiográfico de Jorge Prelorán. Buenos Aires: Ediciones Búsqueda.

Sadoul, G. (1972). Historia del cine mundial, desde los orígenes. México: Siglo XXI editores.

Santiago, L. (2014). Crítica, Maranhão 66. Plano Crítico. 18 de marzo de 2014.

Velleggia, S. (1986). Cine: Entre el espectáculo y la realidad. México: Claves Latinoamericanas.

Xavier, I. (2001). O cinema brasileiro moderno. São Paulo: Paz e Terra.

\section{Filmografía}

Birri, F. (1958). Tire dié. Argentina: Universidad Nacional del Litoral.

Capovilla, M. et al. (1968). Brasil verdade. Brasil: Farkas, T.

Carneiro, M. \& Saraceni, P.C. (1959). Arraial do Cabo. Brasil: Saga Filmes.

de Andrade, J. P. (1959). O mestre de Apipucos: Brasil: Saga Filmes.

de Andrade, J. P. (1959). O poeta do Castelo. Brasil: Saga Filmes.

dos Santos, L. P. (1960). Un dia na rampa. Brasil: Fonseca, E. R. / Primo Carbonari.

Escorel, E. et al. (1970). A condição brasileira. Brasil: Farkas, T. / Pallero, E.

Figueroa, M. J. A. (2008). Trazos en Trozos: Mural Efímero, México 68. México: SyQ producciones.

Gleyzer, R. (1965). Ceramiqueros de Traslasierra. Argentina: Universidad Nacional de Tucumán.

Goldenberg, J. (1963). Reportaje a un vagón. Argentina: Universidad Nacional del Litoral.

Goldenberg, J. et al. (1966). Hachero Nomás. Argentina: Universidad Nacional del Litoral.

González Casanova, M. (1968). Los estudiantes, la Universidad y la violencia (inconclusa). México: Centro Universitario de Estudios Cinematográficos (CUEC).

Hirszman, L. (1964). Maioria Absoluta. Brasil: Leon Hirszman Produções.

Jabor, A. (1965). O Circo. Brasil: Sagitário Produções Cinematográficas Ltda.

Kamffer, R. (1968). Mural efimero. México: Universidad Nacional Autónoma de México.

Kantor, O. (1962). Tierra seca. Argentina: Fondo Nacional de las Artes.

Noronha, L. (1960). Aruanda. Brasil: Noronha e Vieira.

Pereira dos Santos, N. (1955). Río, 40 grados. Brasil: Regina Films Ltda. 
Persano, A. L. (1961). Fiesta en Sumamao. Argentina: Universidad de Buenos Aires.

Prelorán, J. (1965). Casabindo. Argentina: Fondo Nacional de las Artes.

Prelorán, J. (1968). Chucalezna. Argentina: Fondo Nacional de las Artes.

Pussi, D. (1968). Pescadores. Argentina: Universidad Nacional del Litoral.

Rocha, G. (1962). Barravento. Brasil: Iglu Filmes.

Rocha, G. (1966). Maranhão '66. Brasil: Mapa Filmes / Produções Cinematográficas L.C. Barreto.

Rocha, G. (1967). Terra em transe. Brasil: Mapa Filmes.

Saraceni, P. C. (1964). Integração Racial. Brasil: MEC / Setor de Filmes Documentários da DPHAN. 